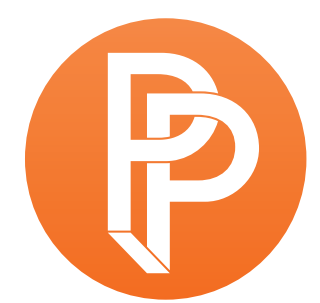

PERFORMANCE

PHILOSOPHY

\title{
INTERVENTION AS INTOXICATION!
}

\author{
RICARDA FRANZEN AND SOPHIE VAN BALEN
}

\begin{abstract}
[...] we are the inhabitants of a culture hierarchized by a logos that knows how to speak but not how to listen and thus constantly avoids genuine dialogue; it primarily tends to induce competing monologues.
\end{abstract}

Fiumara ([1985] 1990, 85; emphasis in original)

When at the end of the 1980s the Italian philosopher Gemma Corradi Fiumara wrote these lines, she did so in the context of developing her philosophy of listening. Today, the notion of 'competing monologues' resonates again with 2020's polarised political climates around the world.

Fiumara's philosophy of listening was proposed as a response to nothing less than the problem of planetary survival and the 'inadequacy of the solutions' on offer at the time (55). This leap from the scale of the interpersonal to the planetary was critiqued at the time as alarmism. Thirty years later, however, the problem diagnosed by Fiumara has dramatically worsened whilst the solutions have remained much the same. The philosopher's search for new methods, then, is as vital now as it was then. Fiumara based her philosophy on 'less customary and less institutionalized areas of research' (41), which we were interested in picking up in the context of Performance Philosophy.

In assembling the diverse perspectives in this journal, we consider it worthwhile to assume a role which Fiumara refers to as 'apprentices of listening' (57). Generally, we allude, through such alternative paths of producing knowledge, to humble ways of responding to socio-political issues. We propose to frame Fiumara's philosophy more specifically as 'listening as intervention', as both a framework for organizing the contents of this edition as well as a recommended attitude for its readers. 
In this journal issue, contributors consider alternative ways of 'intervening'. Originally a military term designating the moment of stepping in during a crisis, the notion of intervention has been transferred to instances of artistic (and) activist acts. ${ }^{1}$ Still, each artwork or act of 'intervention' raises the question of the political anew and we were curious about the Performance Philosophical responses to it, responses that ultimately were developed for the pages of this issue.

The first testing ground for the ideas in this edition was the Performance Philosophy Biennial, which took place in March 2019 in Amsterdam, under the title 'Between Institution and Intoxication: How does Performance Philosophy Intervene?', which we-the guest editors-were responsible for organising. Yet, the conversations and adventures of thinking on the pages of this edition are more than just secondary to or an afterthought of the Biennial. While authors in this issue were also presenters at the conference, we spent the last year virtually together to develop thoughts further and to translate the performance of conference contributions to the predominantly written medium.

\section{Intervention, institution, intoxication}

The central suggestion is to look at intervention through the lens of intoxication. Prominently encapsulated in the title of the Biennial and journal issue we invited contributors to rethink 'intervention as intoxication' as $a$-that is, one possible-way to invoke the ecstatic, inebriated, entangled, and aesthetic dimensions of intervention, and to open a dialogue with a performance/philosophical body of knowledge on intoxication. As the journey of developing a new way of looking at intervention started with a purposefully open and evocative call, responses to it were accordingly heterogeneous. This journal edition maintains the heterogeneity of research areas as well as working contexts, with each contribution specifying and situating the key terms concretely.

In the selection of the ten articles presented in this journal, a number of specific suggestions, questions, and hypotheses are developed. They relate to (the Biennial's) three key terms intervention, institution, and intoxication and resonate with the original conference call. Some article-overarching suggestions which were picked up from our original call mark the thinking experiments in this journal. Anticipating Silvia Bottiroli's essay-which was adapted from her conference keynote presentation-we introduce them here by means of what if-questions.

What if the vocabulary surrounding intervention is no longer adequate for the type of struggle we are encountering and the change we are seeking?

What if 'intervention' takes the shape of addressing structures of symbolic power (such as institutions) beyond critique? What if we left the oppositional logic between institution and intervener behind and instead explore the possibility that we might need institutions or networks to bring about change?

What if intervention was less of a sudden act from the outside inwards, but embodied, slow modification? 
In these pages, we continue the commitment of the arts and humanities to interact with the world and socio-political causes; indeed the arts and humanities have a civil, social, and political role to play. As Gielen and Lijster (2017) argue, this commitment is further mirrored by cultural institutions, who increasingly place themselves in the 'civil sequence' leading from personal anger or despair to public civic engagement or action -and thereby seem to defy the strict opposition between intervener and institution. 'Institutions' are treated as sites and symbolic structures, organizing education, facilitating art, and structuring thought alike. This open-ended definition is voluntary and emphatic, and is differently formulated in the different articles, while it is specifically the relationship with institutions which is under closer scrutiny. Palpably shared amongst several articles is a certain understanding of intervention in its forms of disobedience towards the logic of an institution (Celikates 2016, 44). ${ }^{2}$

In addressing institutions and our (idealist's, intervener's, intoxicator's, critic's) relationship with them, we are parting with the well-known discourse on intervention as the critique of institutions. In this line of thinking, institutions are often seen in Foucauldian terms as symbolic structures of power (White 1985). Since the late 1960s and through to the 2000s, discourses of institutional critique worked on capturing typically interventionist art practices, which inquire critically into (art) institutions, their power structures and workings.

But critique as a way of engagement and mode of practicing thought has come under fire in recent years. Following Latour (2004) among others, there is a need-particularly in academia-to redefine the critical spirit, to stop taking the route of critical distance, but to instead move closer to the observed, and therefore to reflect on the critic's own involvement. For if critique cannot move beyond the untouchable critic (yet-according to this critique of critique-mercilessly unmasking any scientist or scientific fact as being constructed through power), academia is arguably losing knowledge it might not want to lose and gaining the 'wrong' kinds of critics, according to Latour. Or, as Rita Felski reckoned in her work on the limits of critique, decades of academics (and artists for that matter) domesticized critique as the ever recurring gesture of unveiling dominance (Felski $2015,66)$, trapping critique arguably in an inside/outside logic, with the critic's presumed role as that of an outside eye.

The question of modes of engagement and methods of intervention, however, remains concrete and urgent even in departing from critique in its 'original' conception and relation to the Institution. If we (authors, editors, readers) look for engagement with socio-political causes within the environments in which we operate, we might not want to accept that the institutions we move in are by default regarded as not being on the right side of intervention. For how do the whole (of an institution, any institution for that matter) and its parts (individual teachers, students, artists, researchers) relate to each other and to the world?

Unravelling even further, Biennial keynote Nikita Dhawan identified the position of the critic, and potentially the role of critique in relation to institutions, as an exclusionary logic to start with. She 
declared the urge for a new type of intervention, as exemplified through the postcolonial project. In Dhawan's words-spoken during the Biennial-there is a need for 'a shift from street politics as the site of de-subalternization to other areas of intervention (e.g., the postcolonial state, which is like a pharmakon, both poison and medicine). In contrast to the state-phobic rhetoric of protest movements, the relation between the postcolonial state and the subaltern must be reconfigured, thereby converting poison into counterpoison' (Dhawan 2015). ${ }^{3}$

In search of a vocabulary for reconsidering intervention in institutions, this particular dialectic of poison and counterpoison seemed rich and became the proposed notion of 'intoxication', encapsulating for us as conference organisers the possibility to expand the field of intervention beyond the necessarily Western notions of critique, and beyond the polarization between institutions and critics.

\section{Intoxication's currency}

By focusing on intervention as intoxication, we suggest to develop, trace, and/or think different modes of intervening, in the field of arts, in academia (in particular the humanities), and in politics in the broadest sense of the word.

We are aware of the irony of inviting intoxication in and from Amsterdam, where drug consumption has long been a part of its branding. Likewise, we are aware of the many philosophical works on intoxication based on or revolving around a subject's alcohol (Baudelaire, Nancy), hashish (Benjamin), or cocaine (Freud) experience. ${ }^{4}$ However, apart from some reflections on the intoxication of the body, this journal does not deal with the drug-induced discourse as a subject matter. Instead, we follow Walter Benjamin when he contends that the most passionate investigation of the hashish trance will not teach us half as much about thinking (which is eminently narcotic) as the profane illumination of thinking will teach us about the hashish trance' (Benjamin 1999, 216).

Philosophies on and of intoxication usually identify two contrasting and seemingly incompatible experiences of intoxication beyond the chemical and medical understanding. The experience of intoxication is usually considered apolitical because of the subject's altered state. In this common view, intoxication is seen as an escape from society and as severed from sober norms of rational discourse. At the same time, other perspectives-in line with Benjamin-ascribe transformative qualities to experiences of being alienated from the world, creating possibilities for engagement with the world in altered states (Brennan and Williams, 2015).

Nietzsche reminds us of the incompatibility of the two states; regardless, he goes on to think the duality of both states, of (political) individuation (arguably connected to the Apollonian) and (apolitical) ecstasy (of the Dionysian) ([1872] 1992), only one possible example of a sustained duality which authors in this journal discover and work with. 
The urgency of why and how we should rethink intervention at all is something to still address. Alongside the team of conference organizers agreeing that an emerging field such as Performance Philosophy could keep rethinking its own political bias and commitment as well as its institutional entanglements, it was the references to intoxication that gained traction during the Biennial encounters in unexpected and rich ways. While we had instigated the idea of intervention as intoxication based on current examples of artistic acts (e.g. Thomas Bellinck's Domo de Eŭropa Historio en Ekzilo [2013]), it was only through contributions at the Biennial and through the entirety of contributions to this issue that we understood the complex and often paradoxical translations of intoxication into urgent and original forms of engagement addressed through intervention as intoxication.

A theme emerged and took hold which we had anticipated only indirectly through allusions to intoxication as pharmakon: the invitation to think change from within highlighted the paradoxical logic inherent to intoxication-between collectivity and withdrawal, between outward change and internalization thereof, or even ingestion of the intoxicating element. It resulted for the majority of contributions in a reflection upon one's own physical position, the role of one's own body and/or attitude (see pavleheidler; Carolin Bebek, Kate Katafiasz, Karian Schuitema, and Benjamin Weber; Paul Geary; Michael Haldrup, Madeleine Kate McGowan, and Kristine Samson; Simon(e) van Saarloos; Ingrid Vranken).

In working with this paradoxical logic, we recognize the timely acknowledgement of how complexly entangled we all live: climate change (invoked by Haldrup et al. in terms of 'toxic climates' and as a critical interpretation of our suggestion to explore intoxication) is not a topic we choose to be the outside eye on; we are complicit in it; the physical involvement in touching finds its site in a dance class (pavleheidler) as well as in child-rearing (Bebek and Weber); the physical and experiential observations of a human working with plants (Vranken); the radical materiality of violence (Van Saarloos). As editors, we can think of-and admittedly somewhat interpret-this inclusion of positionality, apparent in most if not all papers in this issue, as a relevant response to our time and scholarship.

We think of Donna Haraway's suggestion to trace our plenty and complex entanglements in constructing and developing our reaction, or response-ability, to the world. For with Haraway we ask, "How can we think in times of urgencies without the self-indulgent and self-fulfilling myths of apocalypse, when every fiber of our being is interlaced, even complicit, in the webs of processes that must somehow be engaged and repatterned?" (2016, 35). Interpreting Hannah Arendt's famous analysis of Eichmann's thoughtlessness, Haraway urges that thinking means connecting, it means to place and relate oneself in/to the world around you. ${ }^{5}$ Looking at the world around us, being confronted with irreversible damage to ecosystems of humans and non-humans alike, Haraway reminds us that we are always part of this world, and party to its trouble. Therefore, we echo after her, after Arendt: Think we must. 
And with this point we can connect our observations of the articles with the project mentioned in the beginning: In developing a philosophy of listening, Gemma Corradi Fiumara negotiated the type of knowledge she produced. Her words resonate with the question which we as editors saw emerge in the assembly of articles: through asking how Performance Philosophy might intervene, an emphasis is palpable in many of the articles on ways of knowing. In Fiumara's words:

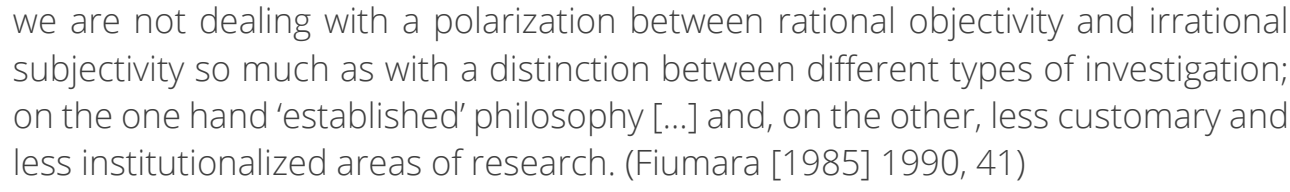

In this journal issue, what becomes readily visible is the search for and commitment to types of investigation, ways of knowing, languages of interpreting, and forms of presenting that are uncommon in academic circles.

This has demanded from us, as editors, but also from reviewers and (most likely) from you as reader, an immense readiness to dive into different contexts and experiments in each article. We evoke one last time Fiumara's 'apprenticeship of listening' in order to mark a humbleness and to open to a paradox or contrast which enables, urges, irritates, or confuses us into thinking afresh: the contrast between the outward and inward direction of involvement and entanglement in institutions; between the established institution of philosophy and new ways of performing knowledge; between individual contribution and collective work in a shared field of study. It is after all not only entanglement and engagement which comes along as association with intoxication, but also the paradox of the pharmakon of poison and counterpoison alike.

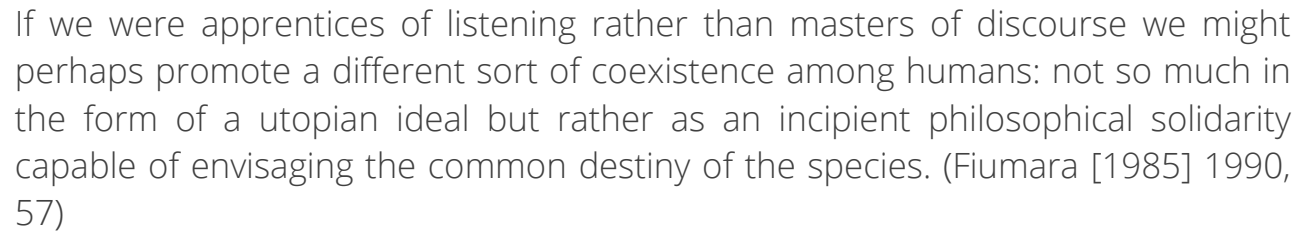

Note

It is not without the productive (in)security of early career academics operating in dependency of several institutions (e.g. peer reviewing), that we here are presenting diverse material by authors from all stages of academic careers. Each argument, or rather thought process, here presented, deserves its own breathing space and context. It is our responsibility to have assembled them together in their loose association with one another. Yet, along with the project of each next to the other comes at the same time a wish and hope to do academia differently.

We invite readers to explore along with us the knowledge(s) that emerge from a wide range of research and forms of presenting it, to get acquainted with new epistemologies, and to attempt listening before critiquing. 
In their collection here, the articles offer a wide spectrum of methods for producing and engaging with knowledge. Following each of them in its own right will require the reader to change methods, contexts, and sites. The articles in this volume-in line with the focus on modes of engagementpurposefully do not continue strictly with established schools of thought, nor is there an explicit emphasis on historical perspectives. The positionality of authors is often part of the reflection.

In terms of our invitation to experiment, some of the contributions maintain explicitly the performative character of the conference (video, dialogue, Q\&A) while others work with traces and ideas of the Biennial by translating them, also in terms of form, to the written medium. That means that in addition to a multidisciplinary assemblage, you will find formal experiments on different scales. One different medium other than writing is presented in the video paper by Michael Haldrup, Kristine Samson, and Madeleine Kate McGowan. You will find a roundtable dialogue (Carolin Bebek, Karian Schuitema, Kate Katafiasz, and Benjamin Weber), a breath-holding experiment interrupting and supporting reflections (Simon(e) Van Saarloos), reflections on the practice of working with plants interspersed with recipes (Ingrid Vranken), as well as poetic layout within a speculative essay (pavleheidler). Writing styles vary purposefully, with a younger generation revealing itself through choice of words, and in some cases intervening into academic style writing with literary and/or journalistic elements.

Throughout the first part of this volume, several contributions both interrogate and concretize our hypotheses on intervention, institution, and intoxication, as well as contribute to rethinking their characteristics.

The relationships between the subject and the world, teacher and student, individual and collective are addressed by, respectively, Daniel Villegas Vélez, Silvia Bottiroli, and Thijs Lijster.

In "Interruption-Intervention: On the interval between literature and music in Jean-Luc Nancy's 'Myth Interrupted,"' Daniel Villegas Vélez proposes to "hear "intervention" and "institution," alongside Nancy's concept of an interrupted community, as part of the project of Performance Philosophy'. In doing so, he rethinks 'to intervene from within' in musical terms. Epistemologically speaking, Villegas Vélez's article can be read as shifting the focus from literature (Nancy) to musical performance.

How does intervention take place on the level of the institution or the Institution? In "A 'What If' Exercise: On the institution of the art school," Silvia Bottiroli engages with the thinking exercise of the "What if" at the site of a specific institution-the art school. She seeks to integrate thinking and performing of such institutions with the progressive/disrupting forces within/inherent to it, tracing their agonistic potential in line with-amongst others-Chantal Mouffe. Thereby, Bottiroli accepts the challenge to think through an institution changing from within. 
In "From the Opium of the People to Acid Communism: On the dialectics of critique and intoxication," Thijs Lijster unpacks the critical distance paradox. He starts from the friction between critical distance and intoxicated engagement, working towards a dual conceptualisation of intoxicated critique and the possibility of critical intoxication, guided by a reading of Walter Benjamin.

Ingrid Vranken and Michael Haldrup, Kristine Samson, and Madeleine Kate McGowan explore the environment and its framing conditions for an altered way of intervening and engaging. Ingrid Vranken offers in "Rooted Hauntology Lab: Attempts at vegetal curation" a reflection on her recent Master's project of working with plants and evokes their ghosts for the reader. She moves from her personal experiences with these plants, such as their apparent silence in contrast with her own human loudness, their different sense of time and slow way of reacting, to curational choices inspired by these observations. The interjection of recipes into the text bares a trace of the performance lecture offered during the conference. The probing of ambiguous humannonhuman-human relationships may be seen to speak from the position of practice to a seminal paradigm shift within theory.

In "Toxic Climates: Earth, people, movement, media," a video contribution by Michael Haldrup, Kristine Samson, and Madeleine Kate McGowan, the authors explore the toxic climates of urban environments, giving attention to the 'intoxicating and dehumanizing forces at play' on the levels of citizenship, mobility and spatial rights, and argue that 'we need remedies for sobering up rather than intoxication'. In using video as their medium, the authors bring theory into action with the positionality of the academic/media activist taking on a particularly self-aware role.

The question of epistemologies, of knowledge(s) that are yet to be institutionalised and might often work with an idea of a body's intoxication, resonates with the contributions by pavleheidler and Paul Geary. pavleheidler speculates on "The Physical Consequence to Knowing: A speculative report," drawing from their experiences as dancer/dance teacher, and from literature by, amongst others, Karen Barad. Thereby, the author counters the institutionalized assumption that puts the 'Enlightened mind over the sacrilegious body'. Examples are drawn from pedagogies and epistemologies which radically include a person's experience and embodied knowledge, such as Body-Mind-Centering ${ }^{\circledR}$. The layout and structure of the article work with interruptions, which arguably fulfils a function similar to the examples of physical practice discussed: 'It is customary for questions to arise, for people's workflow to be interrupted, and for books to be put down. It is customary for the exercises to take more time than anticipated [...].'

In "An-aesthetic: Performed philosophies of sensation, confusion, and intoxication," Paul Geary explores intoxication through the relationship between aesthetics and aneasthesia. The seeming incompatibility is overcome through a close reading of Michel Serres' The Five Senses in combination with the experience of the performance After Dark (2016). In line with Serres, the author suggests 'two modes of knowledge: that of dissecting analysis and that of sensory experience.'

The authors of the last section-Van Saarloos; Hadikoesoemo; Feinberg; and Bebek, Katafisasz, Schuitema, and Weber-each explore different sites and intricacies of intervening from within. 
'Where is the threshold between learning about another person's point of view and becoming complicit through listening?' A vulnerable fine line between empathizing, embodied experience and assuming radical practices is performed in the paper "Blow your mind! Shards hailing, on superfluous violence to stop surviving" by Simon(e) van Saarloos. The author works and engages with examples of violence. The 'hailing shards' of inquiry might hit and miss depending on the reader, while the author reminds us of the open-endedness of their inquiry. In drawing together literature and experience in a way that intervenes consciously in institutions of thinking, the article's style alternates between journalism and academia.

In "Altering Bodies: Thinking of intervention through impersonation," Niki Hadikoesoemo brings the reader to the realm of theatre through examining the actor as a site for what she refers to as 'performative intoxication'. Departing from the canonical texts of Plato's Ion and Diderot's Paradox the author concludes with Lacoue-Labarthe to undermine the passive/active opposition. Hadikoesoemo raises questions such as 'How does the actor's intoxication differ from the audience's? What relation between passivity and activity do we have to presuppose in order for an intoxicating practice to result in intervention? Why is impersonation the intoxicating practice par excellence to provoke catharsis as well as critique?'

In "Understanding Anti-performance: The performative division of experience and the standpoint of the non-performer," Joseph Feinberg introduces several gestures of refusal and resistance to common assumptions, such as on the subversive character of theatre. At the same time, he complicates the idea of anti-theatricality. If Hadikoesoemo looked at the performer, Feinberg is explicitly interested in the perspective of the non-performer. Feinberg brings in Czech philosopher Karel Kosík to think through play as an antidote to theatre and to think (anti-)politics of performance.

In conclusion of this journal, in "On (In)security: A conversation on education and intergenerational dialogues," Carolin Bebek, Kate Katafiasz, Karian Schuitema, Benjamin Weber [and in the background Theo Weber] expand the topic of touch, consent, and intervention to that of (art) education through the intervening/disrupting character of intergenerational dialogue. Their article is an elaborate roundtable version of the Q\&A subsequent to their contributions during the Performance Philosophy Biennial, which ends the journal with a trace of where it started: in the live moment of engagement in Amsterdam 2019. 
1 This is not a new suggestion. Most famously, perhaps, were the Situationists in this respect (Hartmann, Lemke, and Nitsche 2012; Thompson and Sholette 2004).

${ }^{2}$ Celikates problematizes the sharp distinction between conscientious objection and civil disobedience. From this, we take up the idea that intervention, too, might not need to be an active interference, but could also be the refusal to do something.

${ }^{3}$ A version of Nikita Dhawan's keynote was published by the time the Biennial was taking place. If this journal does not follow up on intervention in the context of postcolonial thought more systematically, it is in this case due to circumstance rather than merely conceptualization. In a journal edition occupied with doing 'institutions' differently we can't leave these aspects unmentioned: There were authors who we approached who were not able, partially in too precarious positions, to find the time for the publishing process. And this might be one of the most palpable exclusions a journal as part of the academic institution has to work with: Who is in a position to publish?

${ }^{4}$ The economies of violence and exploitation which Amsterdam's drugs are tied into as well as the modern/ colonial conditions of often quoted texts on intoxication (see Bjelić 2016) need acknowledgment, but are not the focus of this journal. A contribution at the Biennial which dealt with the 'pharmacolonial condition' did so through the 'coloniality of sense' in particular (https://performancephilosophy-amsterdam.n//Macia).

${ }^{5}$ Haraway writes about Eichmann (through Arendt's eyes as it were) "Here was someone who could not be a wayfarer, could not entangle, could not track the lines of living and dying, could not cultivate response-ability, could not make present to itself what it is doing, could not live in consequences or with consequence, could not compost. Function mattered, duty mattered, but the world did not matter for Eichmann" $(2016,36)$.

\section{Works Cited}

Bellinck, Thomas. 2013. Domo de Eŭropa Historio en Ekzilo ('House of European History in Exile'). https://www.robinbrussels.be/domo-de-e-ropa-historio-en-ekzilo

Benjamin, Walter. 1999. Selected Writings: Volume 2, Part 1 1927-1930. Edited by Howard Eiland, Michael W. Jennings, and Gary Smith. Translated by Rodney Livingstone. Cambridge, MA: Harvard University Press.

Brennan, Eugene, and Russell Williams, eds. 2015. Literature and Intoxication: Writing, Politics and the Experience of Excess. Basingstoke: Palgrave Macmillan. https://doi.org/10.1007/978-1-137-48766-7_1

Bjelić, Dušan I. 2016. Intoxication, Modernity, and Colonialism: Freud's Industrial Unconscious, Benjamin's Hashish Mimesis. New York: Palgrave Macmillan.

Celikates, Robin. 2016. "Rethinking Civil Disobedience as a Practice of Contestation—Beyond the Liberal Paradigm." Constellations. An International Journal of Critical and Democratic Theory 23 (1): 37-45. https://doi.org/10.1111/1467-8675.12216

Dhawan, Nikita. 2015. "The Unbearable Slowness of Change: Protest Politics and the Erotics of Resistance." The Philosophical Salon. http://thephilosophicalsalon.com/the-unbearable-slowness-of-change-protestpolitics-and-the-erotics-of-resistance/

Felski, Rita. 2015. The Limits of Critique. Chicago: The University of Chicago Press. https://doi.org/10.7208/chicago/9780226294179.001.0001

Fiumara, Gemma Corradi. (1985) 1990. The Other Side of Language: A Philosophy of Listening. Translated by Charles Lambert. London: Routledge. 
Gielen, Pascal, and Thijs Lijster. 2017. "Art and Civil Action: Cultural Organizations in the European Civil Domain." Visual Ethnography 6 (2): 21-47. https://doi.org/10.12835/ve2017.2-0085

Haraway, Donna. 2016. Staying with the Trouble: Making Kin in the Chtulucene. Durham, NC: Duke University Press: https://doi.org/10.1215/9780822373780

Hartmann, Doreen, Inge Lemke, and Jessica Nitsche, eds. 2012. Interventionen: Grenzüberschreitungen in Ästethik, Politik Und Ökonomie. Paderborn: Fink, Wilhelm. https://doi.org/10.30965/9783846752838

Latour, Bruno. 2004. "Why Has Critique Run out of Steam? From Matters of Fact to Matters of Concern." Critical Inquiry 30 (2): 225-48. https://doi.org/10.1086/421123

Nietzsche, Friedrich. (1872) 1999. The Birth of Tragedy and Other Writings. Edited by Raymond Geuss and Ronald Speirs. Cambridge: Cambridge University Press.

Rose, Gillian. 1997. "Situating Knowledges: Positionality, Reflexivities and Other Tactics." Progress in Human Geography 21 (3): 305-20. https://doi.org/10.1191/030913297673302122

Thompson, Nato, and Gregory Sholette, eds. 2004. The Interventionists: Users' Manual for the Creative Disruption of Everyday Life. Cambridge, MA: MIT Press.

White, Hayden. 1985. Tropics of Discourse: Essays in Cultural Criticism. Baltimore: The Johns Hopkins University Press.

\section{Biographies}

Sophie van Balen is lecturer in the Humanities at the Erasmus University College, Rotterdam (NL). She has a background in political philosophy, philosophy of science and public philosophy and is primarily interested in topics that connect philosophy to contemporary society and its challenges - ranging from climate change to agency and citizenship to knowledge production. Sophie is currently preparing a PhD trajectory on a progressive politics in the face of climate change, grounded in Sloterdijk's foam-ontology.

Ricarda Franzen is lecturer in and coordinator of the Master International Dramaturgy, at the University of Amsterdam (NL) as well as a teacher at the theatre school at ArtEZ in Arnhem (NL). She is a dramaturge by training, working both in radio and theatre, and has a background in rhetoric. She is currently working on a PhD on listening practices and the aesthetics of historical theatre sound recordings.

(c) 2020 Ricarda Franzen and Sophie van Balen 